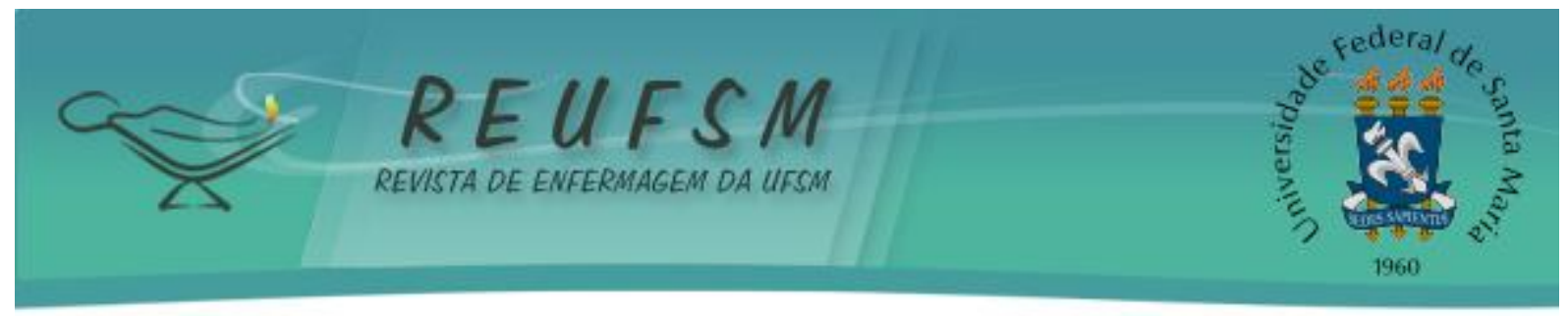

RELATO DE EXPERIENCIA

\title{
SIGNIFICADOS DE MORTE E MORRER NO CURSO DE ENFERMAGEM: UM RELATO DE EXPERIÊNCIA
}

\author{
MEANINGS OF DEATH AND DYING IN UNDERGRADUATE NURSING COURSE: AN \\ EXPERIENCE REPORT
}

SIGNIFICADOS DE MUERTE Y MORIR EN EL CURSO DE ENFERMERÍA: UN RELATO DE EXPERIENCIA

\author{
Stefanie Griebeler Oliveira ${ }^{1}$ \\ Alberto Manuel Quintana ${ }^{2}$ \\ Maria de Lourdes Dernadin Budó ${ }^{3}$ \\ Manoela Fonseca Lüdtke ${ }^{4}$ \\ Paula Argemi Cassel ${ }^{5}$ \\ Shana Hastenpflug Wottrich ${ }^{6}$ \\ Catia Bairro Ferreira ${ }^{7}$
}

RESUMO: Objetivo: este artigo busca relatar a experiência docente das discussões acerca dos significados da morte expressados pelos acadêmicos de enfermagem. Método: essa discussão sobre os conceitos de morte ocorreu na disciplina de Psicologia da Saúde do curso de enfermagem da Universidade Federal de Santa Maria. Participaram da atividade 12 acadêmicos. A metodologia utilizada nos encontros foi a de ação-reflexão. Resultados: a partir dos registros sobre morte para os acadêmicos, foram organizadas sete categorias por aproximação de conteúdo, para melhor apresentar os significados emergidos. São elas: "Alívio para a alma"; "Inexorabilidade da morte"; "Medo do desconhecido"; "Degradação do corpo"; "Experiência da morte do outro: lembranças"; "Naturalidade da morte"; "Designação da morte como nefasta". Considerações Finais: nessa multiplicidade de significados da morte que abarcam as diversas dimensões como biológica, social, psicológica, cultural, os acadêmicos e educador tiveram a oportunidade de construir e transformar seu conhecimento acerca da morte.

Descritores: Enfermagem; Morte; Atitude frente a morte; Ensino; Educação.

ABSTRACT: Objective: this article aims to relate the teaching experience of the discussion about the meanings of death expressed by undergraduate nursing students. Method: such discussion about the concepts of death took place in the discipline of Health Psychology of undergraduate nursing course of Federal University of Santa Maria. Twelve undergraduate

\footnotetext{
${ }^{1}$ Enfermeira. Mestre em Enfermagem. Doutoranda em Enfermagem (UFRGS). Membro dos Grupos de Pesquisa: Cuidado, Saúde e Enfermagem (UFSM); Grupo de Estudos Culturais na Educação em Saúde e Enfermagem (UFRGS). Bolsista Capes. E-mail: stefaniegriebeler@yahoo.com.br

${ }^{2}$ Psicólogo. Doutor em Ciências Sociais. Professor Associado do Departamento de Psicologia e dos Programas de Pós-graduação (mestrado) de Enfermagem e de Psicologia/UFSM. Coordenador do Grupo de Pesquisa Núcleo de Estudos Interdisciplinares em Saúde (NEIS). E-mail: albertom.quintana@gmail.com

${ }^{3}$ Enfermeira. Doutora em Enfermagem. Professor Associado do DENFE e do Programa de Pós-graduação em Enfermagem/UFSM. Pesquisadora do Grupo de Pesquisa Cuidado, Saúde e Enfermagem/UFSM. E-mail: lourdesdenardin@gmail.com

${ }^{4}$ Psicóloga. E-mail: manuludke@hotmail.com

${ }^{5}$ Psicóloga. Mestranda em Psicologia Clínica da Pontifícia Universidade Católica (PUC)- RS. E-mail: paula.acassel@gmail.com

${ }^{6}$ Psicóloga. Mestre em Psicologia. E-mail: shana.wottrich@gmail.com

${ }^{7}$ Pedagoga e Psicóloga. Especialista em Gestão Educacional. Especializanda em Psico-oncologia pela Faculdade de Ciências Médicas de Minas Gerais. Psicóloga da AAPECAN (Associação de Apoio as Pessoas com Câncer). Email: catia.aapecan@gmail.com
} 


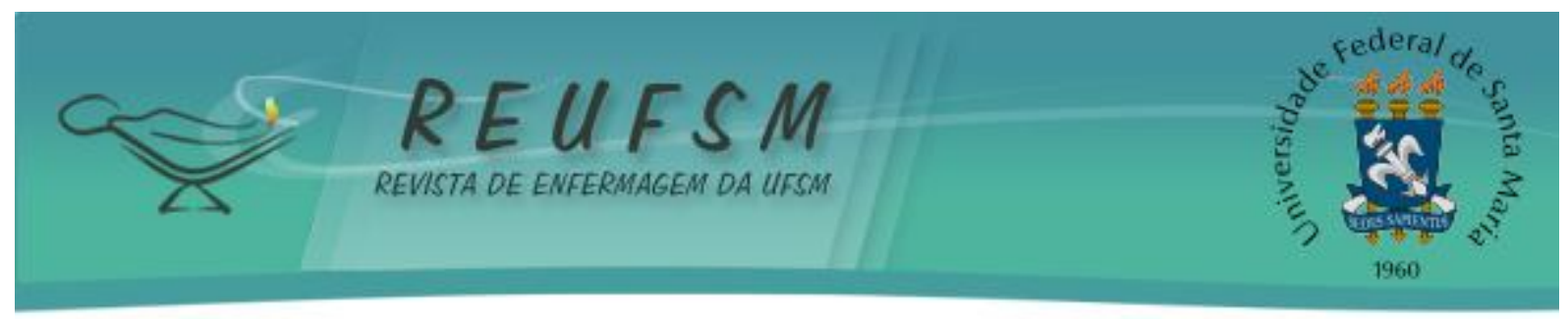

students participated in the activity. The method used in the classes was action reflection. Results: from the reports about death, organized by the students, seven categories emerged, presenting the meanings attributed by them: "Relief for the soul"; "Inexorability of death"; "Fear from the unknown"; "Degradation of the body"; "Experience of another person's death: memories"; "Naturalization of Death"; Designation of Death as something nefarious". Final Considerations: the multiplicity of meanings of death, which concern several dimensions, such as the biological, social, psychological and cultural, allowed the students and the teacher to build and transform their knowledge regarding death.

Descriptors: Nursing; Death; Attitude to death; Teaching; Education.

RESUMEN: Objetivo: este artículo busca relatar la experiencia docente de las discusiones sobre los significados de la muerte expresos por académicos de enfermería. Método: esa discusión ocurrió en la disciplina de Psicología de la Salud del curso de enfermería de la Universidad Federal de Santa Maria. Participaron de la actividad 12 estudiantes. La metodología utilizada en las clases fue la acción reflexión. Resultados: fueron organizadas siete categorías por aproximación de contenido, para mejor presentar los significados surgidos. Son ellas: "Alivio para el alma"; "Inexorabilidad de la Muerte"; "Miedo de lo desconocido"; "Degradación del cuerpo"; "Experiencia de la muerte del otro: recuerdos"; "Naturalidad de la Muerte"; "Designación de la Muerte como nefasta". Consideraciones Finales: en esta multiplicidad de significados de la muerte que abarcan diferentes dimensiones como biológica, social, psicológica, cultural, los académicos y el educador tuvieron la oportunidad de construir y transformar su conocimiento sobre el tema muerte. Descriptores: Enfermería; Muerte; Actitud frente a la muerte; Enseñanza; Educación.

\section{INTRODUÇÃO}

A morte perpassa por dimensões social, cultural, biológica, psicológica. Sendo assim, cada ser humano pode experimentá-la e vivenciá-la de forma diferente. ${ }^{1}$ A partir disso, originam-se os mais diversos significados de morte, sobretudo para os que a experienciam cotidianamente: os profissionais de saúde. Os conceitos de morte fazem parte da temática do processo de morte e morrer, a qual é proposta no cronograma da disciplina de Psicologia da Saúde, do curso de Enfermagem da Universidade Federal de Santa Maria (UFSM), da cidade de Santa Maria/RS, Brasil. Essas discussões viabilizam ao aluno de enfermagem, além da reflexão sobre os conceitos de morte, o pensar nos sentimentos que possam emergir com os enfrentamentos desse fenômeno no cotidiano profissional.

Ressalta-se que o enfermeiro tem papel relevante frente às necessidades que emergem tanto no paciente que se encontra em processo de morte, como na família que o acompanha. 0 cuidado, nessa perspectiva, terá objetivos de conforto, qualidade de vida, e sempre haverá o que fazer nessa situação, sobretudo, ajudando o paciente a morrer de forma mais humanizada. ${ }^{2-3}$

A introdução da discussão da temática da morte no currículo, em suas diversas dimensões, é de certa forma recente nos curso da área da saúde, fato este relevante para uma formação mais humanista, além de possibilitar uma formação profissional na qual a prática não se restringe apenas a salvar vidas, mas também se volta para ajudar pacientes terminais a morrer com dignidade. De fato, porém, a formação é direcionada para a promoção, recuperação e preservação da vida, deixando os futuros profissionais, por conseguinte, despreparados, técnica e psicologicamente, para os enfrentamentos referentes à morte, pois, nesse entendimento, ela não faz parte da vida. ${ }^{4}$ Além disso, estudos $^{4-5}$ revelam que as dificuldades encontradas pelos profissionais de saúde frente à morte decorrem, muitas vezes, da ausência ou pouca discussão sobre o tema entre 


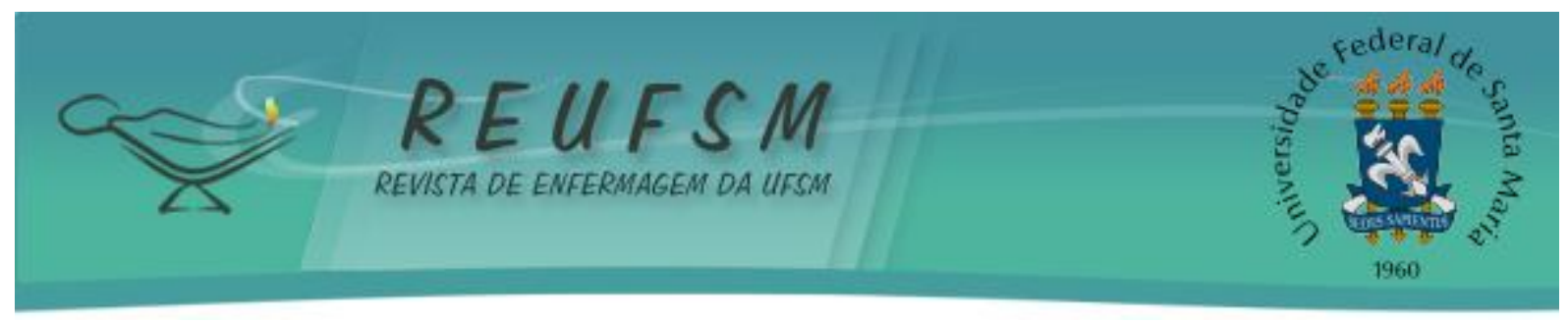

acadêmicos, docentes e trabalhadores. Nessa direção, faz-se necessária a superação das dificuldades encontradas para operacionalizar a discussão da temática da morte. ${ }^{6}$

Diante disso, este artigo trata de um relato de experiência realizada na disciplina de Psicologia da Saúde, do Curso de Graduação em Enfermagem da UFSM. A temática problematizada na experiência abarcou os conceitos de morte. 0 tema foi suscitado tendo em vista a realidade do aluno, e consequentemente posto em discussão, para, finalmente, proporcionar a construção do conhecimento, bem como sua possível transformação. ${ }^{7}$

A proposta de problematização atende ao projeto político pedagógico do curso (PPC) de Enfermagem da UFSM, o qual considera que a aprendizagem, acontecendo a partir da realidade do aluno, proporciona a compreensão dessa realidade, a construção do conhecimento e a possibilidade de transformá-la. Dessa forma, os alunos são atores nesse processo, cabendo-lhes a descoberta, a participação, a autonomia e a iniciativa, no princípio da corresponsabilidade do ensino-aprendizagem. Nessa perspectiva, acredita-se na possibilidade da formação de um profissional com a capacidade de questionar, experimentar e avaliar, que seja crítico e transformador, e que entenda a saúde como um direito de cidadania. Essa metodologia deve constantemente possibilitar a ação-reflexão, proporcionando o diálogo como prática essencial no processo, levando os docentes e discentes a discutir a realidade de forma crítica. ${ }^{8}$

No tocante aos encontros, muitos significados emergiram devido à utilização da pedagogia problematizadora ${ }^{7}$, que oportunizou a expressão de vivências e experiências tanto pelos discentes quanto pelo docente. Com isso, foram promovidas as trocas de conhecimentos, o que possibilitou a construção e transformação da realidade. Nesse sentido, essa experiência propiciou a discussão e reflexão sobre os diversos significados e aspectos que permeiam a morte, o que de fato demonstrou a relevância desses momentos, já que ela faz parte do cotidiano dos profissionais de saúde, sobretudo os de enfermagem. Assim, o presente artigo, pretende relatar a experiência da reflexão/discussão acerca dos significados da morte expressados pelos acadêmicos de enfermagem.

\section{MÉTODO}

0 presente relato de experiência resultou de atividades educativas com discentes da graduação em Enfermagem da UFSM, na disciplina de Psicologia da Saúde, com a participação de 12 alunos. Essas atividades ocorreram no mês de novembro de 2009, durante dois encontros, os quais totalizaram oito horas.

Durante esses encontros foram propostos diversos momentos, sendo amparados pela metodologia problematizadora, uma ferramenta fundamental para a ação-reflexão ${ }^{9}$, inspirada no método do arco de Maguerez. ${ }^{10}$ A prática do docente foi envolvida por processos dinâmicos, que se embasaram no fazer e no pensar sobre o fazer. Tal prática reflete as condições de promover um aprender crítico por meio do pensar transformador dos sujeitos e a reconstrução de saberes de acordo com as reflexões entre educadores e educandos. ${ }^{7}$

No primeiro encontro, foi solicitado aos discentes que registrassem de maneira anônima significados, experiências e vivências acerca do processo de morte e morrer. Após, esses registros foram devolvidos à docente da disciplina, e logo redistribuídos entre os discentes de forma que não ficassem com suas anotações primárias, a fim de realizarem argumentações de concordância ou discordância sobre o escrito. No terceiro momento, foram recolhidos novamente os registros e, posteriormente, a turma foi dividida em quatro grupos. A estes, disponibilizaram-se quatro artigos científicos distintos ${ }^{11-14}$, que discutiam a temática do processo de morte e morrer.

0 momento de leitura e discussão entre os grupos foi uma etapa de teorização ${ }^{10}$ referente às questões levantadas (pontos-chave) ${ }^{10}$, inicialmente, a partir das vivências e experiências registradas pelos alunos. Em seguida, foram redistribuídos novamente os registros, 


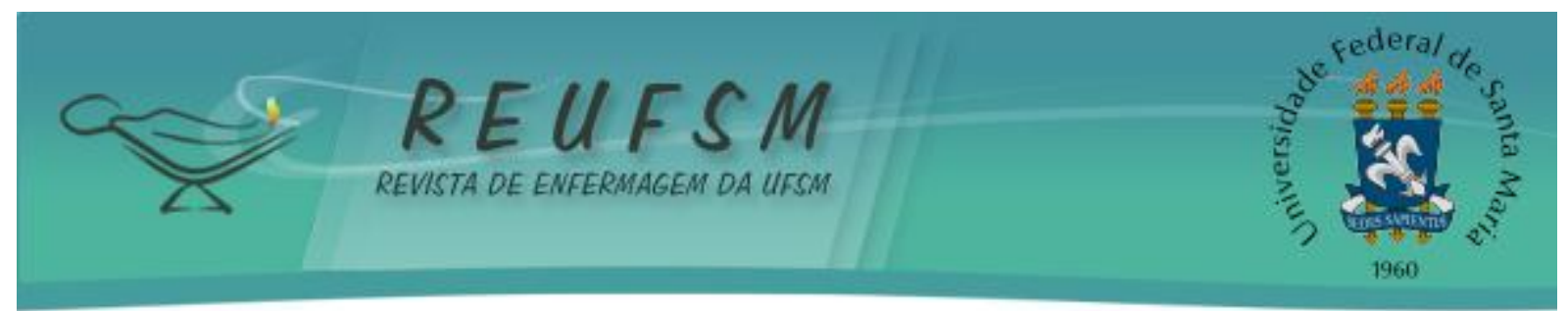

para a associação da teoria abordada nos artigos com a realidade percebida pelos discentes. Depois se iniciou uma discussão com o grande grupo, abordando os significados do processo de morte e morrer, transformando, assim, a realidade, na construção de novos significados. ${ }^{10}$

No segundo e último encontro proporcionou-se uma avaliação teórica, na qual cada discente expressou a construção e transformação de seu conhecimento acerca do processo de morte e morrer. Essa avaliação verificou se houve a ampliação das concepções frente a essa temática. Os diversos significados acerca da morte e morrer que emergiram foram organizados em sete categorias. A organização dessas foi feita através de aproximações entre essas significações, para melhor apresentar as múltiplas facetas que envolvem essa etapa final da vida.

\section{RESULTADOS E DISCUSSÃO}

As sete categorias elaboradas pela aproximação de ideias representam os significados da morte para os acadêmicos. São elas: "Alívio para a alma"; "Inexorabilidade da morte"; "Medo do desconhecido"; "Degradação do corpo"; "Experiência da morte do outro: lembranças"; "Naturalidade da morte"; "Designação da morte como nefasta".

\section{Alívio para a alma}

A morte, na fala de alguns discentes, por muitas vezes, se torna a melhor saída para a pessoa, visto que ela estaria em grande sofrimento psíquico e físico, geralmente devido a alguma enfermidade crônica. Nessa perspectiva, a morte se torna produtiva, por aliviar os sofrimentos de um indivíduo doente.

Em um estudo realizado, os enfermeiros acreditavam que a morte era um alívio para aquele indivíduo que estava sofrendo devido a alguma doença. Os enfermeiros sentiam-se aliviados ao acreditar em vida após a morte, pois essa crença alivia os sentimentos de perda do paciente, os quais são substituídos pela sensação de "descanso espiritual", quando se concebe que o espírito do paciente descansará em outra dimensão. ${ }^{15}$ Nessa direção, a espiritualidade, quando é central na vida da pessoa, pode vir ao encontro das suas necessidades, com o oferecimento de histórias, crenças e práticas que, por sua vez, vêm facilitar a formulação de um mundo subjetivo e significativo que atua em uma realidade construída e pessoal face à doença, incapacitação ou morte. ${ }^{16}$

Implicitamente, esse alívio pode ser tanto para o doente como para quem está à sua volta, tendo em vista que a doença, de alguma forma, atinge também as pessoas próximas do enfermo. Assim, quem descansa não é somente quem morre. Todavia, a crença em vida após a morte é apenas uma hipótese, o que pode fortalecer, de certa forma, a cultura de negação da morte, pois faz com que o indivíduo não pense que é um ser finito.

\section{Inexorabilidade da Morte}

A inexorabilidade da morte exprime sua face implacável, colocando-a no status de algo que obrigatoriamente irá ocorrer. Nas discussões realizadas, foi recorrente o sentido de que a morte é algo inevitável e apresenta-se para o ser humano como a única certeza que se tem sobre a vida, ou seja, de que um dia ela terá um fim, sem escapatória.

De fato a morte é inevitável e, além disso, universal, ou seja, acontecerá com todos. A morte e a vida separam-se por uma linha extremamente tênue no desenvolvimento humano. Todos os seres vivos podem percorrer o caminho do nascimento, da juventude, maturidade, velhice, doença e morte, mas apenas os seres humanos possuem consciência de seu fim. Logo, a existência humana é acompanhada da certeza da morte. ${ }^{11}$ 


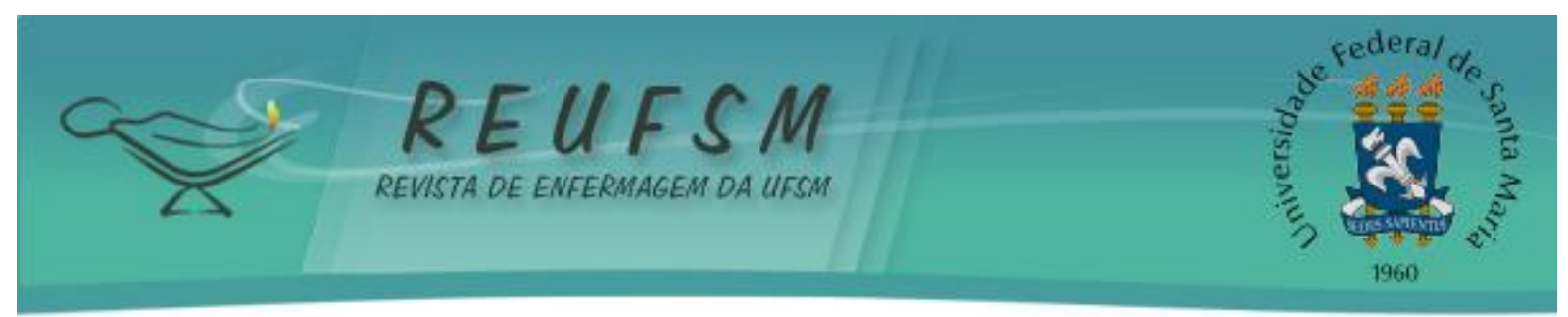

Diante disso, se o ser o humano entende a morte com uma das únicas certezas da vida, e é o único ser vivo que possui consciência de seu fim, por que não a enfrenta com "naturalidade"? Por que, mesmo para os profissionais de saúde que enfrentam esse fenômeno diariamente na experiência da morte do outro, é tão difícil aceitá-la? Como será possível introduzir os cuidados paliativos que entendem a morte como processo natural, se o ser humano tem dificuldade de aceitá-la? São questões que precisam ser trabalhadas de forma transversal ao longo do curso de enfermagem e no cotidiano profissional, pois, para a introdução dessa forma de cuidado, é necessário que o paciente, a família e os profissionais aceitem a morte.

\section{Medo do Desconhecido}

É notável que, em relação à morte, o sujeito apresenta duas crenças contraditórias. Ao mesmo tempo em que tem a certeza de que a morte ocorrerá, se apresenta nele o questionamento sobre o que pode ocorrer após o fim da vida, o que implica numa continuidade da mesma e, portanto, a crença na continuação da existência. Assim, ele acredita que vai morrer, mas simultaneamente pensa que, após essa morte, vai continuar vivendo. Esse mecanismo é conhecido na psicologia como "denegação", uma forma pela qual o sujeito se protege da angústia gerada pela morte, mas, por outro lado, não incorre numa negação total da mesma. ${ }^{17}$ Este misto de sensações gera o medo do não saber, presente nas falas dos estudantes. Esse medo pode ser visto como um medo de não poder sustentar a sua crença sobre uma continuidade da vida, a qual anularia a ideia da morte como um fim.

0 medo da morte configura-se como universal, sendo que o medo da própria morte revela a consciência do ser humano de sua própria finitude e a fantasia de como e quando ocorrerá. ${ }^{5} \mathrm{~A}$ partir disso, pode-se inferir que o ser humano, ao pensar e falar sobre a morte, expressa medo pelo fato de não desejar a sua própria morte e a de outras pessoas que lhe sejam próximas afetivamente.

Somando-se a esse contexto, nota-se que o sentimento de estranheza, o qual perpassa a morte, explica-se por não se ter nela a mesma concretude presente na vida. 0 desconhecido gera medo do que há por vir e, nesse sentido, afastar-se de tudo que lembre a morte e suas interrogações é a melhor solução, ocasionando um falso sentimento de segurança e colocando a morte no âmbito do inefável.

A parada total das funções, das atividades, ou seja, a possibilidade de aniquilação da existência do indivíduo, também produz sentimentos de confusão, medo e repulsa frente à morte. 0 medo da morte pode ser remetido à possibilidade de aniquilação da existência, o que é expresso detalhadamente numa obra de Tolstoi ${ }^{18}$, em seu protagonista, Ivan llitch. Nessa história, esse personagem relata seu processo de morte e morrer, revelando angústias, momentos de esperança de cura de sua doença, e, sobretudo, o medo da aniquilação de sua existência.

0 medo da morte é permeado ainda por aspectos culturais e religiosos, já mencionados anteriormente, como a crença em vida após a morte. Contudo, a crença oscila com dúvida sobre se realmente existe algo após o final da vida. Assim, o medo do desconhecido faz com que as pessoas criem explicações para diminuir seu desconforto frente ao mistério que envolve a morte. Dentre as mais conhecidas maneiras, estão as crenças religiosas que tentam explicar o que ocorre após a morte. Além disso, observa-se que esse medo também é permeado pelas reflexões sobre o sentido da vida, da aniquilação de existência.

\section{Degradação do corpo}

Percebe-se que, além de questões emocionais e simbólicas, a morte também é perpassada pelo aspecto biológico que é intrínseco a ela. Isso procede pelo fato de que o cessamento das funções vitais representa a materialidade do fim da vida, podendo ser em decorrência das doenças ou pela idade avançada. 


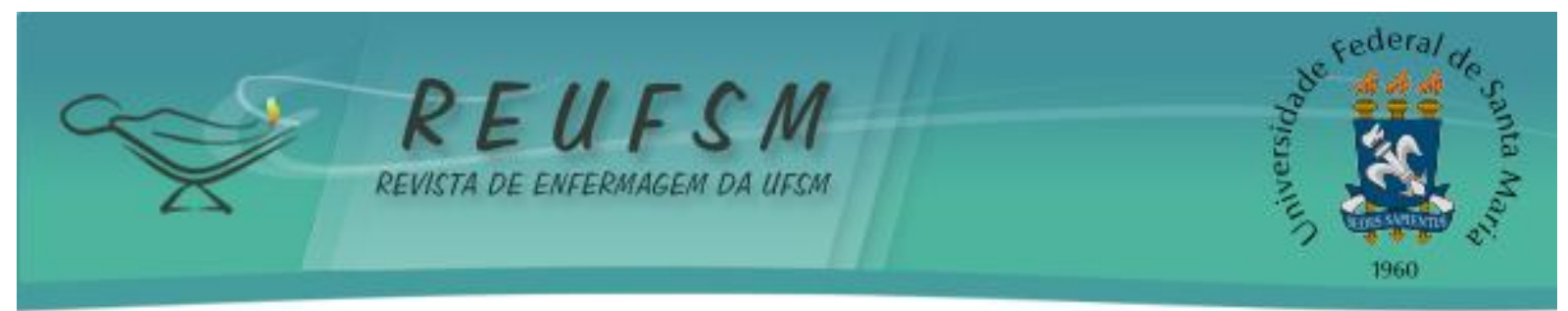

A morte do outro é revelada pelo cadáver que apodrecerá, o que denuncia a existência de um corpo como matéria e representa a finitude da vida humana. 0 cessamento das funções vitais presentifica a morte, ou seja, delineia o inevitável. ${ }^{11}$

A morte biológica consolida o aspecto mais concreto desse fenômeno, já que com o encerramento das funções orgânicas, o indivíduo não poderá mais se relacionar com as demais pessoas, ficando apenas na memória delas. Estas lembranças refletem os aspectos psicossociais da morte.

\section{Experiência da morte do outro: lembranças}

A morte é sempre experienciada com a morte do outro, o que deixa lembranças e memórias às pessoas que ficam em vida. De fato, a morte do outro não acarreta em sua finitude completa, uma vez que aqueles que ficam, através da lembrança, mantêm viva a pessoa que faleceu, em seu sentido simbólico.

A morte do outro desperta o medo do abandono e envolve a consciência da separação e ausência física. Assim, há uma vivência da morte, não de si mesmo, mas como se parte de si morresse junto com a morte do outro. ${ }^{5}$ Além disso, a morte do outro é uma lembrança da própria morte, e nisso consiste a dificuldade das pessoas em dar àqueles que estão morrendo a ajuda e afeição de que necessitam, para se despedir dos seus entes queridos. ${ }^{11}$

A dor sentida pela morte de alguém exprime uma saudade, um desejo de estar junto novamente. As lembranças, nesse sentido, confirmam o fim da vida, e o não fim do existir simbólico. Por outro lado, essa dor também manifesta que lembrar da morte do outro é reafirmar o que tanto se quer esquecer: a própria morte. Sendo assim, entende-se que, frente às lembranças, aquilo que era visto de fora, como algo que acontece somente com os outros, agora é atingível também a este sujeito que se recorda de alguém já falecido.

\section{Designação da morte como nefasta}

Grande parte das opiniões expressadas durante a discussão revelou que a morte possui uma conotação negativa, sendo atribuído a ela o fardo de ser algo ruim, triste, e difícil de ser enfrentado. Ao longo dos anos a concepção de morte sofreu modificações. No passado, era vista como algo familiar, que deveria ocorrer dentro de casa, sendo respeitada em todos os seus aspectos. No presente, ela torna-se vergonhosa, inconveniente, algo que deve ser ocultado. Dessa forma, as pessoas passam a perceber a morte como feia e suja. ${ }^{11}$

Para o homem ocidental moderno, a morte passou a ser identificada como fracasso, impotência e vergonha. Há uma tentativa de ultrapassá-la a qualquer custo e, quando se evidencia que isso não é possível, ela é negada. ${ }^{14}$ Acredita-se que um dos aspectos que nutre a cultura de negação da morte relaciona-se com o aumento da perspectiva de vida frente às evoluções tecnológicas, produzindo essa fantasia de onipotência contra a morte. ${ }^{13}$

Esta perspectiva cultural de negação da morte teve como resultado o tabu em relação a ela sendo que, na atualidade, tenta-se desmistificá-la para que a mesma seja entendida como um processo natural. $O$ fato de pensar que a morte é um fracasso faz parte dos discursos produzidos pela sociedade atual, a qual valoriza a juventude, a vitalidade, a saúde, a produção, entre outras características próprias desse contexto. Em contrapartida, um novo paradigma emergente, a ciência dos cuidados paliativos, que busca entender a morte como natural, a fim de proporcionar um fim digno para os pacientes terminais, vem fazendo movimentos discretos no meio da saúde. 


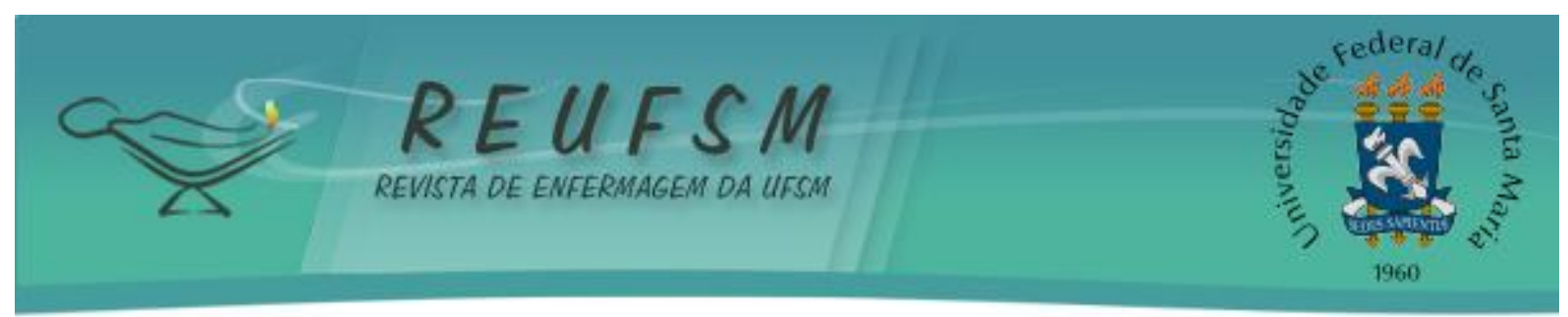

\section{Naturalidade da morte}

A morte também foi entendida como um evento natural que pertence ao ciclo vital. Sendo assim, ela faz parte do desenvolvimento humano, e não é algo externo à vida. Isso pode acarretar em uma mudança de paradigmas frente ao tema da morte, e assim permitir a reflexão sobre ela.

Todo ser vivo nasce, se desenvolve e morre. Este é o ciclo da vida e tentar mascarar a morte é o mesmo que ignorar que ela faz parte da vida, embora represente o fim da mesma. Entender que a morte é algo natural, do ponto de vista biológico, permitirá aceitá-la e poderá abrir brechas para reflexões a respeito desse fato. ${ }^{11}$

Além disso, esse entendimento irá permitir a implantação de cuidados paliativos para indivíduos que se apresentem em estágio terminal, já que, para desenvolver essa modalidade de cuidado na sua totalidade, todos os envolvidos devem aceitar a morte com naturalidade, desde o paciente e família, até os profissionais de saúde que proporcionarão esses cuidados.

\section{CONSIDERAÇÕES FINAIS}

Diante dos conceitos de morte que emergiram nos encontros, observou-se que, frente a esta multiplicidade de significados, os acadêmicos de enfermagem e o educador obtiveram a oportunidade de trocar informações, construir e transformar o conhecimento acerca do processo de morte e morrer. Além disso, a discussão sobre a temática, na metodologia problematizadora, foi avaliada como imprescindível e fundamental pelos acadêmicos, já que o assunto havia sido pouco discutido anteriormente, em suas vidas cotidianas.

No decorrer dos encontros, os acadêmicos relataram que falar sobre a morte traz dúvidas, desconfortos e diversos questionamentos sobre a própria existência. Contudo, expuseram que o debate da temática é fundamental para formação profissional, uma vez que trabalharão com situações que envolvem a morte e, desmistificando-a, conseguirão aceitar os limites de sua profissão, assim podendo ajudar as famílias e os pacientes terminais no processo de morte e morrer.

Somando-se a isso, fica evidente que a experiência individual e pessoal exerce expressiva influência no pensamento que cada um tem sobre a morte. Parece haver uma ambivalência de sentimentos acerca da abordagem da temática, na medida em que entendem ser necessária, porém difícil, a apropriação da realidade da finitude. Nesse escopo, o caminho a ser percorrido na formação do enfermeiro parece ser o de admitir e compartilhar tais sentimentos, abrindo espaço para ressignificações da morte também no âmbito da vida pessoal. Entende-se que, se os acadêmicos tocaram-se ao falar sobre a morte em sala de aula, possivelmente, ao se depararem com essa realidade em sua prática profissional, sentir-se-ão acometidos por esses sentimentos de insegurança, desconforto. Tais sentimentos devem ser acolhidos e compreendidos à luz das experiências singulares dos indivíduos, buscando encadeamentos de significados em suas vidas.

\section{REFERÊNCIAS}

1. Frutos MM, Iglesias GJA, Frutos MJM, Calle PA. La persona en el proceso de muerte. Enferm glob. 2007;(10):1-14.

2. Oliveira SG, Quintana AM, Dernardin Budó ML, Bertolino KO, Kruse MHL. A formação do enfermeiro frente às necessidades emergentes da terminalidade do indivíduo. Rev enferm UFSM [internet]. 2011 [acesso 2011 jan 31];1(1):97-102. Disponível em:

http://cascavel.ufsm.br/revistas/ojs-2.2.2/index.php/reufsm/article/view/1996/1519. 


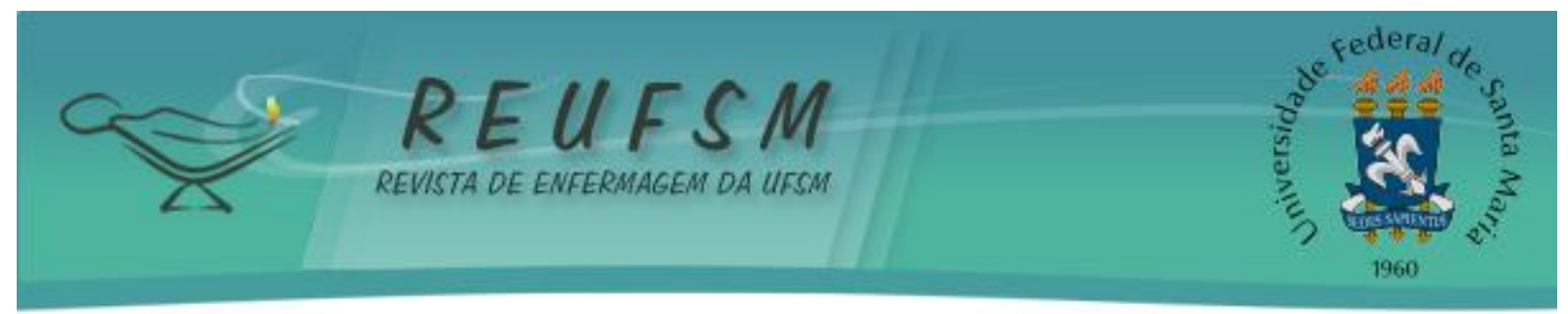

3. Oliveira SG, Quintana AM, Bertolino KO. Reflexões acerca da morte: um desafio para enfermagem. Rev bras enferm. 2010;63(6):1077-80.

4. Bellato R, Araújo AP, Ferreira HF, Rodrigues PF. A abordagem do processo do morrer e da morte feita por docentes em um curso de graduação em enfermagem. Acta paul enferm. 2007;20(3):255-63.

5. Brêtas JRS, Oliveira JR, Yamaguti L. Reflexões de estudantes de enfermagem sobre a morte e o morrer. Rev. Esc Enferm USP. 2006;40(4):477-83.

6. Carvalho MDB, Valle ERM. Vivência da morte com o aluno na prática educativa. Ciênc cuid saúde. 2006;5 Supl:26-32.

7. Freire P. Pedagogia da autonomia: saberes necessários à prática educativa. São Paulo: Paz e Terra; 2009. 148 p.

8. Universidade Federal de Santa Maria. Projeto Pedagógico do Curso de enfermagem: estratégias pedagógicas. Santa Maria: Curso de Graduação em Enfermagem; 2005.

9. Silva JLL, Assis DL, Gentile AC. A percepção de estudantes sobre a metodologia problematizadora: a mudança de um paradigma em relação ao processo ensino aprendizagem. Rev eletrônica enferm. [internet]. 2005 [acesso 2010 jan 11]; 7(1):72-80. Disponível em: http://www.revistas.ufg.br/index.php/fen.

10. Bordenave JED. La transferência de tecnologia apropriada al pequeño agricultor. Revista Interamericana de Educação de Adultos. 1983;3(1-2):75-102.

11. Bellato R, Carvalho EC. O jogo existencial e a ritualização da morte. Rev latinoam enferm. 2005 jan-fev;13(1):99-104.

12. Souza LB, Souza LEEM, Souza AAM. A ética no cuidado durante o processo de morrer: relato de experiência. Rev bras enferm. 2005 nov-dez;58(6):731-4.

13. Oliveira AC, Sá L, Silva MJP. O posicionamento do enfermeiro frente a autonomia do paciente terminal. Rev bras enferm. 2007 maio-jun;60(3):286-90.

14. Combinato DS, Queiroz MS. Morte: uma visão psicossocial. Estud psicol. 2006; 11(2):209-16.

15. Magalhães AVL, Silva RCL. Los conceptos de muerte y morir en enfermería y las relaciones con el ethos del cuidado. Enferm glob. 2009;(17):1-10.

16. Daaleman TP. Religion, spirituality, and the practice of medicine. The Journal of the American Board of Family Practice. 2004;17(5):370-6.

17. Laplanche J, Pontalis JB. Dicionario de psicoanálisis. Barcelona: Labor; 1968.

18. Tolstoi L. A morte de Ivan Ilitch. Porto Alegre: L\&PM Pocket; 2008.

Data de recebimento: $26 / 07 / 2011$

Data de aceite: 14/09/2011

Contato com autor responsável: Stefanie Griebeler Oliveira

Endereço: Alvaro Batista-1583. São Luiz Gonzaga/RS.

CEP: $97800-000$

E-mail: stefaniegriebeler@yahoo.com.br 